\title{
Coccidioidomicose: novo caso brasileiro
}

\author{
Coccidiodomycosis: a new Brazilian case \\ Mário A.P. Moraes, Ricardo Luiz M. Martins, Isabel Irene Rama Leal, Inesila \\ Schettini Rocha e Pedro Medeiros Junior
}

\begin{abstract}
Resumo É descrito um caso de coccidioidomicose pulmonar oriundo da zona rural de Bertolínia, PI. A manifestação clínica principal consistiu em dor torácica e o diagnóstico teve por base o achado do agente - Coccidioides immitis - em cortes histológicos. Formas teciduais do microrganismo - esférulas imaturas e maduras - estavam presentes nas lesões observadas em fragmento pulmonar removido do paciente por biópsia a céu aberto. Este novo caso autóctone da doença, como os outros anteriormente descritos no Brasil, procedia do interior semi-árido da Região Nordeste. O ambiente quente e seco do sertão nordestino oferece, sem dúvida, condições propícias ao desenvolvimento de $\mathrm{C}$. immitis, um habitante do solo. As pessoas e animais do local devem adquirir a infecção ao revolver a terra, ato que os expõe à poeira contendo os propágulos do fungo.
\end{abstract}

Palavras-chaves: Coccidioidomicose. Coccidioides immitis.

Abstract A case of pulmonary coccidioidomycosis from the rural zone of Bertolinia, $P I$, is reported. The patient, a farm worker, attributed his illness to the dust inhaled while digging a water well during the dry season of the year, some weeks before the onset of the clinical manifestations. The main symptoms of the disease were severe chest pain and moderate fever. The diagnosis was made histopathologically: tissue phase fungal organisms - immature spherules and spherules with endospores - were observed in histological sections of a lung fragment obtained by open chest biopsy. This is the twelfth autochthonous case of coccidioidomycosis found so far in Brazil. All of them involved native inhabitants of the semi-arid part of Northeastern Brazil. The hot and dry environment of the region seems to favor the development of $\mathrm{C}$. immitis in the soil. Humans and animals probably acquire the infection by digging the soil, when they become exposed to the conidium-bearing dust raised by this activity.

Key-words: Coccidioidomycosis. Coccidioides immitis.

Hospital Universitário de Brasília, Brasília, DF.

Endereço para correspondência: Dr. Mário A.P. Moraes. Hospital Universitário de Brasília, Via L2 Norte, SGAN 605, Mod. 70840-050 Brasília, DF.

Fax: (061) 272-3250.

Recebido para publicação em 01/12/97. 
A coccidioidomicose é uma infecção sistêmica, primariamente pulmonar, causada pelo fungo dimórfico Coccidioides immitis. Quase sempre de natureza benigna e resolução espontânea, os casos da doença passam em geral despercebidos, o que tem dificultado o reconhecimento de novas áreas endêmicas. Formas graves, disseminadas - nas quais pode haver comprometimento cutâneo - , facilmente identificáveis, raras vezes são observadas.

C. immitis, na natureza, está associado a ambientes semi-áridos, de temperaturas altas na estação seca - bastante longa - e chuvas escassas, concentradas em curto espaço de tempo. Por esse motivo, tem a doença distribuição geográfica limitada e transmissão restrita a alguns meses do ano. Zonas de alta endemicidade ocorrem no sudoeste dos Estados Unidos e norte do México. Focos endêmicos de menor importância existem na América Central (Guatemala e Honduras) e na América do Sul (Argentina, Paraguai, Bolívia, Colômbia e Venezuela). No Brasil, poucos casos autóctones foram até agora referidos2 3456789 , todos procedentes da Região Nordeste. Neste relato é descrito um caso de coccidioidomicose oriundo do Estado do Piauí e diagnosticado pela histopatologia.

\section{RELATO DO CASO}

RMP, 29 anos, sexo masculino, pardo, lavrador, natural e procedente de Bertolínia, Estado do Piauí. Em junho de 1996, veio ao Hospital Universitário de Brasília (HUB), por causa de dor torácica e febre, manifestações surgidas cerca de nove meses antes. Atribuía esses distúrbios à poeira inalada durante a abertura de um poço, na época seca do ano anterior. Um irmão que o auxiliara nessa tarefa apresentou também, na mesma ocasião, alterações respiratórias de natureza branda.

Ao procurar assistência médica no local onde morava, um radiograma do tórax mostrou nódulos pulmonares difusos e, embora a pesquisa de bacilos acidorresistentes no escarro tivesse sido negativa, foi ele tratado, por quase seis meses, para tuberculose. Não havendo melhoria do quadro clínico, procurou ajuda médica em Brasília, onde o diagnóstico de tuberculose, a principio mantido, não pôde ser confirmado. Devido, entretanto, à persistência da dor, que já se irradiara para todo o tórax, foi ele encaminhado ao HUB.

No momento da admissão, referiu dor torácica, febre inconstante - acompanhada de calafrios e sudorese - cefaléia e ligeira perda de peso (cerca de cinco quilogramas desde o início da doença). Negou tosse, expectoração e dispnéia. Espirometria e gasometria dentro dos padrões normais. Parecia em bom estado geral e a única alteração visível eram lesões eritêmato-vesiculosas nos lábios (herpes simples). Novo radiograma confirmou a presença do infiltrado nodular difuso, bilateral, visto anteriormente (Figura 1).

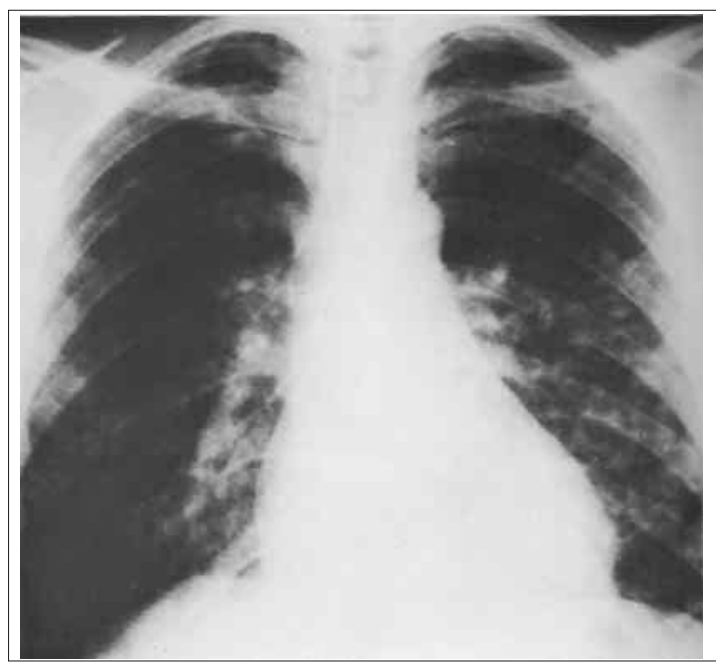

Figura 1 - Radiograma dos pulmões: infiltrado nodular difuso, bilateral.

Em 03/06/96, praticou-se uma biópsia pulmonar transbrônquica, mas a histopatologia acusou apenas inflamação crônica não-específica da mucosa bronquial. Decidiu-se, então, fazer nova biópsia, a céu aberto, levada a cabo no dia 02/07/96.

Os cortes histológicos mostraram vários granulomas e extensas áreas de necrose fibrocaseosa no parênquima pulmonar (Figura 2). Corpúsculos arredondados, de membrana espessa (PAS-positiva) e tamanho variável, alguns aparentemente vazios e outros fragmentados, podiam ser vistos, esparsamente, nas áreas necrosadas. Destacavam-se, entre eles, estruturas maiores, com $50 \mu \mathrm{m}$ ou mais de diâmetro, contendo formações esféricas bem delimitadas, os endosporos (Figuras 3 e 4). Esses corpúsculos foram identificados como esférulas imaturas e maduras de Coccidioides immitis. 


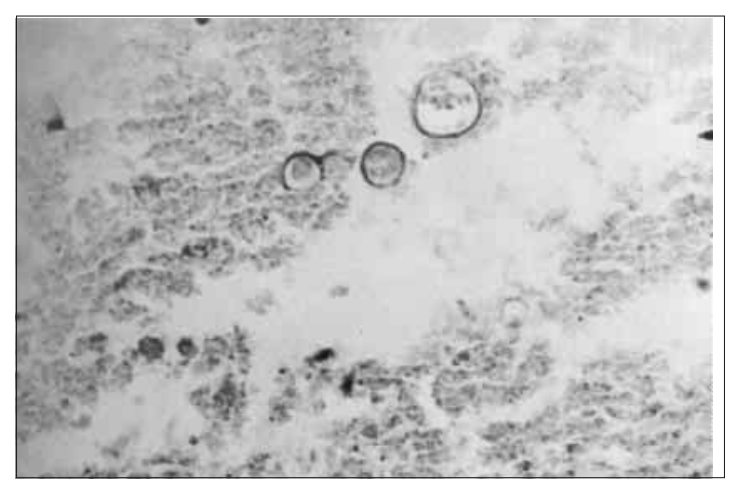

Figura 2 - Área de necrose no pulmão, contendo várias esférulas de C. immitis. HE 200x.

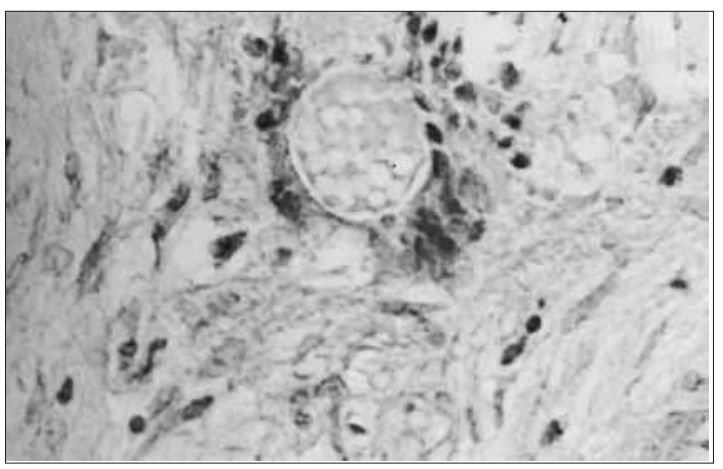

Figura 3 - Esférula madura: vários endosporos aparecem no interior do microrganismo. HE 400x.

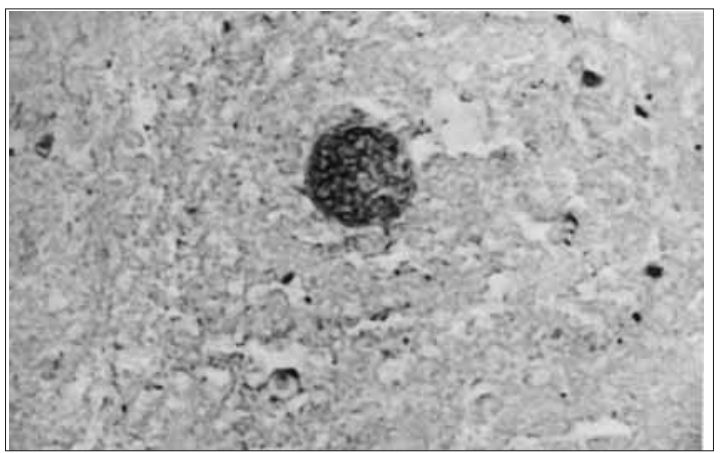

Figura 4 - Esférula madura, após coloração pelo ácido periódico-Schiff. 200x.
Firmado o diagnóstico de coccidioidomicose, tanto o paciente como o irmão - cuja sintomatologia declinara espontaneamente passaram a fazer uso do cetoconazol, $400 \mathrm{mg} / \mathrm{dia}$, a partir de agosto de 1996. Logo depois ambos retornaram ao Estado de origem, porém soube-se, em dezembro, pelo irmão - ele voltara a Brasília em busca de emprego - que os dois continuavam sob tratamento e que a dor torácica do paciente diminuíra sensivelmente.

\section{DISCUSSÃO}

A existência no Brasil da coccidioidomicose foi constatada no final dos anos 70, pelo achado consecutivo de dois casos autóctones, ambos procedentes da Região Nordeste. O paciente do primeiro $\mathrm{caso}^{2}$, descrito em 1978, era natural de Paripiranga, BA, mas residia, havia seis anos, em São Caetano do Sul, SP. Com sintomatologia respiratória importante, manifestada nesse período, fora ele submetido, durante algum tempo, a tratamento para tuberculose, embora os testes específicos tivessem sido negativos. $\mathrm{O}$ do segundo $\mathrm{caso}^{8}$, referido alguns meses depois, procedia das imediações de Floriano, PI (Vianna H: comunicação pessoal, 1997), e viera para o Distrito Federal cerca de um ano antes do reconhecimento da doença. O diagnóstico, nos dois casos, teve por base a demonstração do fungo em cortes histológicos de tecidos pulmonares.

Aproximadamente quinze anos depois desses achados - únicos até então - uma microepidemia em caçadores de tatus, envolvendo três pessoas - dois adultos e um menino de dez anos -, além de oito cães, foi observada na zona rural de Oeiras, PI9. Amostras de solo, coletadas no mesmo local escavado para desentocar os tatus, permitiram o isolamento de $C$. immitis.

No caso seguinte 3 , oriundo de Jaguaribara, $\mathrm{CE}$, o paciente apresentava lesões na laringe, com diagnóstico inicial histológico de carcinoma espinocelular ceratinizante. Nos cortes foram vistas esférulas, identificadas como de $C$. immitis. Sem lesões pulmonares, o paciente faleceu alguns anos depois, aparentemente em conseqüência de disseminação da neoplasia. Inquérito intradérmico com esferulina ${ }^{1}$, levado a efeito na localidade (Poço Comprido) onde o paciente tinha vivido, revelou uma positividade de $11,5 \%$, em 87 habitantes, na leitura do teste após 48 horas. A propósito, antes, em 1978, Lacaz et al 4 haviam realizado estudo semelhante, 
no Hospital das Clínicas de São Paulo: em 393 pacientes submetidos ao teste - representando diferentes regiões do Brasil —, apenas um mostrou reatividade à esferulina. Tratava-se de mulher nascida em Muritiba, BA, mas residindo em São Paulo, SP, havia nove anos.

Em 1997, Martins et al5 apresentaram novo caso procedente do Nordeste. O paciente era de Monte Santo, BA, e havia seis anos viera para São Paulo, onde, em 1996, a doença foi diagnosticada pelo achado do fungo no escarro, ao exame direto e cultura. Estudos sorológicos confirmaram o diagnóstico.

Ainda em 1997, Silva et al7 descreveram um surto epidêmico em Aiuaba, CE, compreendendo quatro pacientes, que pouco tempo antes tinham estado envolvidos em uma caçada de tatus. Dos quatro, em apenas um foi a doença comprovada pelo isolamento de $C$. immitis do escarro. Nos outros três, o diagnóstico se baseou em evidências radiológicas e/ou epidemiológicas. Dois cães que acompanharam os pacientes na caçada nada apresentaram. Os quatro pacientes dessa microepidemia foram reapresentados por Sidrim et al6, em artigo incluindo o Nordeste brasileiro entre as zonas endêmicas de coccidiodomicose.

A origem comum dos casos brasileiros até agora conhecidos, inclusive o da presente descrição - em todos a infecção estava associada a locais situados na zona semi-árida da Região Nordeste - indica que o sertão nordestino deve ser considerado como mais uma área endêmica de coccidioidomicose na América do Sul. O clíma quente e seco dessa área, com temperaturas elevadas na maior parte do ano e precipitação escassa, concentrada no período de alguns meses, oferece, sem dúvida, condições favoráveis ao desenvolvimento de C. immitis no solo.

A contaminação se dá pela inalação de artroconídios do fungo, suspensos no ar, fazendo parte da poeira levantada quando a terra é revolvida. Na maioria dos casos, a infecção evolui sem qualquer manifestação clínica e passaria completamente despercebida não fosse a conversão do teste intradérmico à coccidioidina. Formas sintomáticas, dependendo da intensidade dos distúrbios, têm sido tomadas, sem dúvida, por diversas afecções respiratórias, principalmente a tuberculose, nos casos mais graves.

Pode-se agora esperar que a difusão do conhecimento sobre a ocorrência dessa vasta área endêmica de coccidioidomicose no nordeste do Brasil concorra - ao incluir a infecção por $C$. immitis no diagnóstico diferencial de doenças respiratórias - para o achado de novos casos, os quais, certamente, mostrarão a real importância da micose na nosologia regional.

\section{REFERÊNCIAS BIBLIOGRÁFICAS}

1. Diógenes MJN, Jamacuru WF, Silva MAB, Carvalho FF. Inquérito epidemiológico com esferulina em Jaguaribara, CE, Brasil, 1993. Anais Brasileiros de Dermatologia 70:525-529, 1995.

2. Gomes OM, Serrano RRP, Pradel HOV, Moraes NLTB, Varella ALB, Fiorelli AI, Espósito I, Saad FA, Furlaneto JA, Rothman A, Espósito MA. Coccidioidomicose pulmonar. Primeiro caso nacional. Revista da Associação Médica Brasileira 24:167-168, 1978.

3. Kuhl IA, Kuhl G, Londero A, Diógenes MJN, Ferreira MF. Coccidioidomycosis laríngea: relato de caso. Revista Brasileira de Otorrinolaringologia 62:48-52, 1996.

4. Lacaz CS, Salebian A, Melhem MSC, Mendes MJS, Takahashy N, Heins EM. Inquérito imunalérgico com esferulina em um hospital geral de São Paulo. Revista da Associação Médica Brasileira 24:403-404, 1978.

5. Martins MA, Araújo EMPA, Kuwakino MH, HeinsVaccari EM, Del Negro GMB, Vozza Jr. JA Lacaz CS.
Coccidioidomycosis in Brazil. A case report. Revista do Instituto de Medicina Tropical de São Paulo 30:299-304, 1997.

6. Sidrim JJC, Silva LCI, Nunes JMA, Rocha MFG, Paixão GC. Le Nord-Est Brésilien; Région d'endémie de coccidioïdomycose? A propos d'une microépidémie. Journal de Mycologie Médicale 7:37-39, 1997.

7. Silva LCL, Nunes LMA, Sidrim JJC, Rios Gonçalves AJ. Coccidiodomicose pulmonar aguda. Primeiro surto epidêmico descrito no Ceará - Segundo no Brasil. Jornal Brasileiro de medicina 72:49-66, 1997.

8. Vianna H, Passos HV, Sant'ana AV. Coccicioidomicose. Relato do primeiro caso ocorrido em nativo do Brasil. Revista do Instituto de Medicina Tropical de São Paulo 21:51-55, 1979.

9. Wanke B. Coccidioidomicose. Revista da Sociedade Brasileira de Medicina Tropical 27 (supl. IV):375-378, 1994. 